\title{
«Tener vida en las letras». \\ Verdad, ficción y alegoría en la épica del xvi
}

\author{
Lara Vilà \\ Universitat de Girona \\ lara.vila@udg.edu
}

Jerónimo Corte-Real

Sepúlveda e Lianor. Canto Primeiro

(edición y estudio preliminar de Hélio J. S. Alves)

Coimbra, Centro Interuniversitário de Estudos Camonianos, 2014, 201 p.

ISBN 978-989-8660-04-6

Juan de Mal Lara

Hércules animoso

(edición preliminar, notas y edición crítica de Francisco Javier Escobar Borrego, prólogo de Juan Montero)

México, Frente de Afirmación Hispanista, 2015, 1833 p.

ISBN 978-84-616-9268-2 (3 volúmenes)

Largo es el camino que ha recorrido el estudio de la épica culta en el ámbito ibérico desde el siglo XIX, en el que no pocas voces aseveraban la falta de poemas heroicos auténticos. No obstante, desde que Cirot (1946) apuntase la pertinencia de leer la épica como una forma de historiografía, autores como Pierce (1968) y Chevalier (1966) abrieron la senda de una renovada mirada crítica que, en particular y muy atinadamente, planteaba la necesidad de acercarse al género desde las coordenadas culturales de su escritura. A partir de la década de 1970 diversos autores se esforzaron por devolver a la épica ibérica su antiguo esplendor (Caravaggi 1974; Prieto 1979), y a principios del nuevo siglo se sucedieron las aportaciones a su estudio (Lara Garrido, 1999; Davis, 2000; Alves, 2001; 
Vilà, 2001). Lejos de agotarse, la recuperación de la épica ha mantenido su interés y ha propiciado acercamientos de orden diverso (Vega-Vilà 2010; Blanco 2012), ha conocido números monográficos (como el de Criticón en 2012 y el que verá la luz en Bulletin Hispanique) y ha visto crecer las ediciones de poemas épicos que hasta entonces no habían conocido versión moderna.

La presente reseña se ocupa de dos de las más recientes ediciones de poemas épicos peninsulares. Su interés radica ya no sólo en la circunstancia feliz de que podamos por fin leerlas, en especial en el caso de la obra de Juan de Mal Lara, inédita hasta hoy, sino muy en particular porque ambas permiten ilustrar la diversa naturaleza que conoció la escritura épica quinientista así como la complejidad de su recepción. La primera en ser tratada será la versión realizada por Hélio J. S. Alves sobre el que es un «triste caso»: el Sepúlveda de Jerónimo Corte-Real, autor de obra en portugués y en español. El poema trata de la historia de amor y muerte de la pareja formada por António de Sousa de Sepúlveda y Leonor de Sá. Podría sorprender que el escritor que había celebrado la victoria cristiana en Lepanto y la portuguesa en el cerco de Diu se ocupe de un suceso familiar y luctuoso, que tan alejado está en apariencia de la materia heroica. Y que recurra para ello a la introducción de episodios mitológicos y fantásticos que tanto disgustaron a la crítica que se había ocupado de la obra. La defensa realizada por el editor es, así, toda una declaración de intenciones. Pondera la merecida fama de Corte-Real, oscurecida por la de Camóes, y la pertinencia de una forma de escritura épica, calificada de «sublime», que puede leerse en clave histórica y política en el contexto de la anexión portuguesa, ayudando a perfilar una visión más cabal de la épica ibérica.

Porque al cabo, como señala Juan de Mal Lara en la dedicatoria de su Hércules animoso, de lo que se trata es de «tener vida en las letras» («Al muy alto y muy poderoso señor don Carlos, príncipe de las Hespañas, nuestro Señor, p. 306), ya que, como señalan todos los poetas del período, sólo estas salvan del olvido la memoria de las grandes hazañas o de acontecimientos dignos de merecerla. La tarea del escritor deviene, a manos del humanista sevillano, un pilar para el sostenimiento de la monarquía, porque la épica sirve a las naciones a la manera de la historia, como en este caso, por medio del elogio del monarca. Pero el modo elegido en el Hércules, esto es, la asimilación de las gestas hercúleas a la trayectoria imperial, ilustra también una escritura consciente de la empresa intelectual que acompaña a la elección del género que, no hay que olvidarlo, mantiene tradicionalmente un fuerte vínculo con la exegesis alegórica. Para Mal Lara no basta con la verdad de lo relatado bajo el manto de la alegoría. Debe auspiciarse con ella el sostenimiento de la virtud y, de ahí, que «los que estudiamos y queremos nombre de letras» deban procurar «que lo mejor que se hallare en nuestros libros, según la facultad de cada uno, se escoja y aparte lo mejor». Y de los «libros fingidos» puede deducirse un comportamiento ejemplar ya que «la virtud sacó en él su retrato verdadero» (Ibid., 305-306). Así, la ficción, la fábula mitológica, como ocurre también en el caso 
del Sepúlveda, completa la relación histórica y sostiene una finalidad superior que no colisiona con ella sino que plantea una forma, más culta y sofisticada, de relatarla.

Jerónimo Corte-Real

Sepúlveda e Lianor. Canto Primeiro

(edición y estudio preliminar de Hélio J. S. Alves)

Coimbra, Centro Interuniversitário de Estudos Camonianos, 2014, 201 p.

ISBN 978-989-8660-04-6

Este primer volumen del poema de Jerónimo Corte-Real augura una edición que, una vez completada, está llamada a ser la versión de referencia del último poema épico de Jerónimo Corte-Real. Estamos, sin duda alguna, ante un proyecto ambicioso y de una envergadura sin precedentes en la historia editorial del autor portugués al que la omnipresente sombra camoniana de Os Lusíadas había prácticamente desterrado al olvido. Al responsable de la edición, el profesor Hélio J.S. Alves, debemos los esfuerzos más notables de la crítica reciente por resituar la figura de este poco conocido pero importante poeta de la literatura portuguesa y española del Quinientos, y su extensa y erudita obra al respecto, publicada a lo largo de hace más de una década, lo convierten en la máxima autoridad en la materia. Como explicita el editor en el prólogo al extenso estudio introductorio que abre el volumen, el lector tiene en las manos una edición comentada de una obra que modernamente sólo podía encontrarse en la versión preparada por Lello \& Irmao en 1979, pero cuyo lujoso formato no le hace justicia. Por encima de todo, Alves quiere responder a una larga tradición crítica que había postergado la calidad poética de Corte-Real y edita el que en su opinión es su mejor poema épico. En este sentido, estamos, a no dudarlo, ante el fruto de una línea de investigación continuada, sólida y, casi diría, vital.

Siendo esta la finalidad primordial de la edición, no sorprende en absoluto que el primero de los apartados de la Introducción esté dedicado a arrojar algo de luz sobre la importancia de Corte-Real en la literatura del Quinientos, y más concretamente en el contexto de las tensas y complicadas relaciones de Portugal con el reino vecino de España. Con el título de «Se não tendes notícia de Jerónimo Corte-Real...", este apartado no es una biografía al uso sino un estudio de las circunstancias históricas y literarias relativas a la elección de la temática del Sepúlveda, que, por lo tanto, se circunscriben al período final de la vida del poeta, entre las décadas de 1570 y 1580 , marcadas por la anexión política de Portugal por parte de la corona española tras la llorada muerte del rey don Sebastián en Alcazarquivir (1578). Recuerde el lector que el Sepúlveda no se ocupa de la narración de hechos bélicos ni gloriosos, la materia común con que suele forjarse la épica europea del Renacimiento, sino que la trama podría calificarse antes de trágica, en tanto que narra la historia de Manuel de Sousa de Sepúlveda y Leonor de Sá y el naufragio 
y muerte de ambos y sus hijos en la región de Natal, en el sur de África, cuando regresaban a Portugal desde Goa. La documentación manejada por el editor ilustra la importancia política que Corte-Real tuvo para Felipe II, a quien, no olvidemos, había dedicado su extenso poema sobre la victoria lepantina, acabado en 1575 y publicado en Lisboa en 1578, lo que la tradición interpretó como un signo de la hispanofilia del autor. Contra esta visión, el editor apunta otra distinta y muy sugerente, cuyo interés radica en proponer una lectura en clave historiográfica del poema, que convierte la semblanza biográfica en un posicionamiento exegético cercano a las presuposiciones del género: la obra, lejos de aclarar el supuesto colaboracionismo del autor esgrimido por la crítica, ilustra más bien «numa História de erros ético-políticos internos ao reino e na perdição colectiva final» (36).

Esta lectura se conjuga con una primera aproximación estilística con la que el editor suele sentirse particularmente cómodo, como ya ha demostrado en estudios anteriores, y en la que suele descollar gracias a su atención por el detalle. En el segundo apartado del estudio preliminar, la defensa del Sepúlveda como ejemplo del estilo sublime enlaza con el tratamiento del problema de la maravilla grecolatina en la épica cristiana, uno de los aspectos más recurrentes y debatidos de la teoría de la épica del Quinientos. De la recensión de la trama destaca el editor algunos de los momentos líricos y alegóricos que lo jalonan, como por ejemplo, la descripción inicial del nacimiento de la heroína y su caracterización psicológica durante el primer encuentro con el que será su marido en el canto I; la funesta descripción de la casa del Odio del canto III, que culmina con el asesinato de Luís Falcão, rival amoroso del protagonista; la célebre descripción de Leonor del canto IV rememorada por Cervantes en el Persiles; o las celebraciones de la boda premonitoriamente marcadas por el desfile de la corte infernal del Canto V... Son momentos líricos e intensos, que completan la psicología de los personajes. Marcados en un inicio por la presencia de la mitología clásica, esta será sustituida por la imaginería cristiana y las profecías dinásticas y nacionales en los cantos finales. Todo ello nos permite hablar de un poema rico y complejo, que aborda una variedad de temas, registros y niveles de significación que, sin embargo, fue objeto de censura por parte de la crítica, en particular, como le ocurriera a Os Lusiadas, en lo concerniente al uso de la maravilla pagana. Para demostrar que estos episodios no son decorativos ni secundarios en la construcción semántica y estructural del poema, sino un instrumento al servicio de la universalización de una historia podríamos decir que doméstica y poco épica, Alves singulariza el pasaje del canto XVI que narra el encuentro de Sepúlveda con el espectro de su hijo muerto, convertido en «consolo posível que a natureza concede aos infelices e, no mesmo momento, o sinal patente que os condena» (47), que permite leer la desgracia sufrida por la célebre pareja como justo castigo por la muerte de Luís Falcão.

Abandona el editor las disquisiciones estilísticas en el siguiente apartado para rastrear la fortuna del poema en diversos escritores, todos ellos espańoles, entre 1594 y 1640. Siendo un apartado relevante para demostrar la injusta postergación de Corte-Real por parte de la crítica, se percibe aquí cierta ruptura discursiva y 
quizá esta sección hubiera debido seguir más lógicamente a la semblanza biográfica. El estudioso ilustra aquí por medio de citas y pasajes paralelos la profunda impresión que el poema sobre el desastre de Sepúlveda y Leonor causó entre sus contemporáneos y seguidores más inmediatos. Tal es el caso de Pedro de Mariz en sus Diálogos de Vária História (1594); de Lope de Vega en la Arcadia (1598) y, sobre todo, el Laurel de Apolo (1630), donde los pasajes paralelos se multiplican; de Cervantes en el Viaje del Parnaso (1614) y el Persiles (1617); de Calderón en A secreto agravio, secreta venganza (ed., 1637); o de Juan de Solórzano en su obra histórico-jurídica Disputationes De Indiarum Jure (1629) y de Tirso de Molina en sus Escarmientos para el cuerdo (ed. 1636). Alves hace una lista apretada de obras literarias o generales en el que es uno de los apartados más extensos de esta introducción, lo que demuestra el interés del editor por rescatar la figura del poeta haciendo una revisión concienzuda de autores contemporáneos que reescribieron sus versos, sobre todo en la literatura espańola de la época, asediada ya por cierto en diversos ensayos que preceden a este.

Alves ha considerado desde la publicación de su tesis doctoral (2001) que el Sepúlveda es la mejor obra del poeta. Una de las principales razones que sostienen dicha valoración es de orden estilístico, de ahí que el siguiente capítulo, dedicado al que llama el «Modo Fácil», se dedique con profusión a analizar la escritura corte-realina por medio del asedio de diversos ejemplos. En ellos se ve que el poeta rehúye toda afectación buscando sencillez y una llaneza aparentemente descuidada: no hay giros expresivos violentos, ni léxico oscuro y difícil. El texto no parece presentar especiales dificultades al lector. Sin embargo, como revisa el editor en un largo subapartado titulado "O estilo em análisis», la facilidad de lectura no está reñida en absoluto con un conocimiento refinado de las técnicas de la composición poética, con un trabajo de lima extraordinario, como la revisión de ejemplos del Sepúlveda analizados exponen con claridad. La mejor poesía, cabe concluir, es aquella que no lo parece, la que dice mucho con poco y que el editor considera una muestra del «diletantismo aristocrático» (89) y la modernidad de Corte-Real. Pero más allá de este supuesto dandysmo, que explicaría la despreocupación del portugués por consignar teóricamente este modo de escritura tan "cortesano», lo interesante es la lectura que Alves propone de este «modo fácil», porque, dice, semejante elección no es sólo estilística. Tras ella late un deseo más profundo y de naturaleza moral, que aparece explicitado en la magnífica comparación de dos pasajes paralelos, que pueden interpretarse como muestra simbólica de la elección de un modo de escritura y de sus implicaciones. Se trata de las descripciones del Templo de la Verdad (canto X) y del Templo de la Mentira (canto XI). El primero es un templo sin adornos pero «majestuoso», «simple» pero «severo y venerable», cuya visión satisface al protagonista (Não vê muito artificio, mas um grave,/Singelo e fácil modo que o contenta, X, 349-350). El segundo es un «edificio soberbio y admirable», ricamente adornado y diseñado según dicta Vitrubio, es decir, ha sido levantado por mano sabia y es un templo perfecto, pero moran en él los hipócritas. La oposición es toda una declaración 
de intenciones, que el editor lee a la luz de la carta que Sepúlveda escribe a Leonor en el canto I. En esta misiva no hay palabras artificiosas ni elevadas pero ofrece «mil verdades» (I, 784). Por ende, la conclusión a la que llega Alves es muy interesante: Corte-Real busca "os fundamentos éticos de escrita artística» y los encuentra en la «máxima atenuação possível do carácter artificioso da poesía», siendo "sua manifestação mais sublime» y audaz (82) porque esta sencillez es la base arquitectónica de la verdad.

El estudio introductorio se cierra con los criterios seguidos en la edición, entre los cuales destaca la explicación de los seguidos para establecer el título, que constituye, en realidad, una lectura del poema en el sentido apuntado en el segundo apartado, sobre el estilo sublime del Sepúlveda. El descriptivo título que recibió el poema en su primera edición (Naufrágio e Lastimoso Sucesso da Perdição de Manoel de Sousa de Sepúlveda e Dona Lianor de Sá, sua mulher, e filos, vindo da India para este Reino na nau chamada o galeão grande S. João que se perdeu no Cabo de Boa Esperança, na terra do Natal. E a peregrinação que tiveram rodeando terras de Cafres mais de 300 léguas té sua norte. Composto em verso heróico e octava rima por Jerónimo Corte-Real) resultaba ya incómodo en la época por ser demasiado largo y, de hecho, en los diversos documentos relativos a su publicación se manejaban otras opciones más concisas. Muchas de ellas enfatizaban la idea del naufragio, quizá por el interés que el asunto despertaba en los años en que la obra llega a la imprenta. Siendo un poema póstumo, desconocemos cuál sería el título definitivo que Corte-Real le habría dado, de modo que Alves opta por ofrecer una variante que responda mejor a su lectura. En su opinión, el poema no versa sobre el naufragio de la pareja protagonista y sus hijos, porque, de ser así, no parecen tener explicación los cinco primeros cantos, en los que se nos narra un capítulo crucial como es el de la muerte del rival de Sepúlveda. La importancia concedida al naufragio por el impresor lisboeta de la primera edición responde pues a una operación comercial, pero una lectura más atenta revela claramente que el tema es la narración del castigo y la expiación del asesinato de Luís Falcão. El título que da Alves a su versión, Sepúlveda e Lianor, ilustra una idea muy ajustada de lo que es la tarea del editor crítico, según la cual la versión del poema debe dar cuenta del mayor número de elementos posible, lo que en este caso implica conceder la centralidad a los protagonistas. De este modo cobran sentido esos momentos que la crítica consideraba superfluos pero que, al cabo, sirven a la caracterización psicológica de ambos personajes, edificada a partir de unos pasajes alegóricos que, lejos de ser meros adornos, son parte esencial de la construcción del poema. Son, en suma, la traslación poética del estado anímico de la pareja (como es el caso de la descripción de la Isla de la Venganza, reflejo de los celos que devoran al protagonista y que se consumarán en el crimen del prometido de Leonor). Conceder centralidad a la pareja apunta también a cuestiones genéricas importantes, tales como la relación liminar que la épica ha mantenido con otro tipo de narraciones más o menos afines, o sin las cuales no se explica una tradición basada en la imitación y contaminatio de mo- 
delos. La importancia central de la relación amorosa de los protagonistas enlaza, así, con la compleja relación que, a lo largo del Quinientos, la épica mantiene con las narraciones conocidas como romanzi y con la vigencia de la tradición helenística de los relatos bizantinos. Al explicar las razones que justifican no seguir servilmente la tradición editorial del poema, Alves plantea pues una visión muy certera de lo que debe ser la tarea de un editor, atento a la diversidad de elementos que intervienen e influyen en la creación del texto.

En cuanto a la edición, modernización y notas, la edición de Alves refleja una atención por el detalle mínimo muy notable. El canto I, único de este primer volumen, está precedido por todos los materiales preliminares (licencias, privilegio, prólogo al lector y dedicatoria y un soneto de Estêvão Ribeiro a António de Sousa) y por un breve resumen del argumento, con indicación de versos. Pero si algo merece especial mención es la anotación del poema, extensa, profusa y de naturaleza tan diversa que casi podría calificarse de anticuaria, en el mejor de los sentidos, y cuya función principal es, como explicita el propio editor, "contribuir para interpretaçóes bem fundamentadas do poema e das suas partes, mas sem entrar nas interpretaçóes propriamente ditas, as quais devem ficar para a liberdade do leitor» (12). El lector encontrará pues notas de una naturaleza diversa y completísima: interpretativas, gramaticales, contextuales, estilísticas, que aportan una información precisa y detallada para construir una lectura del poema. Destacable y preciosa es pues la labor del profesor Alves, cuya continuación aguardamos expectantes.

Juan de Mal Lara

Hércules animoso

(edición preliminar, notas y edición crítica de Francisco Javier Escobar Borrego, prólogo de Juan Montero)

México, Frente de Afirmación Hispanista, 2015, 1833 p.

ISBN 978-84-616-9268-2 (3 volúmenes)

Meritoria es también la labor llevada a cabo por el profesor Escobar en la edición del hasta ahora inédito poema épico-alegórico que el humanista Juan de Mal Lara escribió en distintas fases entre 1549 y 1565. Estamos ante una tarea que indudablemente podemos calificar de hercúlea, como afirma Juan Montero en el prólogo para la edición del FAH, y que recupera para los lectores de hoy un capítulo importantísimo de las letras sevillanas del Quinientos, pero muy en particular de la épica hasbúrgica del siglo xvi. Se trata del único poema, que se sepa hasta el momento, que aborda el elogio de las hazañas de Carlos V bajo el velo de la alegoría, para lo que recurre a la narración de las célebres tareas del personaje mitológico al que la Casa de Austria consideraba uno de sus ancestros míticos. La obra se divide en doce libros, respetando el número y la ordenación clásica de los trabajos de Hércules y la no menos canónica de la Eneida, si bien, 
como explica el profesor Escobar en el resumen del argumento (26-28 y 267), el episodio del descensus ad inferos, que es el de mayor carga política, se desarrolla en último lugar. Así pues, el Hércules es la única de las Caroleidas, los poemas épicos sobre el Emperador, que no se ciñe a la relación de la historia contemporánea sino que, a diferencia de Sempere, Zapata y Urrea, opta por leerla en clave mitológica aunque respetando la cronología de los acontecimientos narrados. Así, por ejemplo, las primeras hazañas del León de Nemea y la Hidra de Lerna son el correlato de la llegada de Carlos V a Espańa en 1522 y la respuesta imperial a la rebelión de las Comunidades; el Jabalí de Erimanto es el manto alegórico que cubre al rey de Francia, Francisco I; el sometimiento de la Cierva es una alusión al dominio de las Indias, etc. La edición del poema, extensísimo y riquísimo en alusiones de todo tipo, que se analizan en el no menos detallado estudio preliminar, más allá de recuperar una obra hasta ahora perdida de uno de los grandes humanistas del siglo, deviene una pieza infaltable para completar el panorama de la épica española del Renacimiento y no podemos más que celebrar los esfuerzos del profesor Escobar para que finalmente haya visto la luz.

El poema es uno de los más extensos, junto con el Carlo famoso de Luis Zapata, de la épica hispana. Supera las cinco mil octavas y Mal Lara se preocupó, además, de dotarlo de un completo aparato exegético de naturaleza diversa que incluye índices, argumentos, tablas de autores y vocablos oscuros y una Declaración cercana a la tradición comentarista, entre otros materiales paratextuales. Es, en suma, un empeño de gran envergadura que buscaba dotar a España de un poema épico digno de su calidad imperial pero que a su vez sólo se concibe en el marco de la visión humanista de la épica. No en vano, por otra parte, coincide la redacción del poema con el regreso de su autor a Sevilla y el reencuentro con el círculo académico hispalense, cuya importancia en la elaboración del poema y sus paratextos estudia Escobar en el interesante apartado «Sevilla en el Hércules animoso». Así pues, Mal Lara, postula el editor, contemplaría dos posibles tipos de lector para su obra: al más docto se dirige, en definitiva, el grueso de los materiales que deben de guiar una interpretación más profunda y de cuño moral, aunque sometida a una intencionalidad política principal. Semejante lectura, por otra parte, se vincula con la defensa de la oscuridad poética, acorde con su lector ideal, y perfila una idea de la intención ética de la obra. En cuanto a la interpretación política, abordada por el editor en el apartado final de su estudio («Interpretación y significado»), trata aspectos cruciales de la tradición épica que pasan por la atención a la liminariedad del género con otras especies edificantes y pedagógicas, tales como los specula principis, que acercan la lectura del Hércules a $L a$ Psyche. Esta lectura cívica se muestra también atenta a la ortodoxia cristiana, en un intento del autor por soslayar posibles censuras inquisitoriales. Resume todo ello Escobar como sigue: "Mal Lara concibe su poema como un artefacto literario trufado de doctrina cristiana e ideología política, lo que le permitirá abogar por la transmisión al lector de una enseñanza, por lo general, con un tono sentencioso» (278). Son cuestiones relevantes para enmarcar la 
lectura del Hércules en el contexto de la tradición genérica a la que pertenece y que el editor esboza aquí en dos apartados que a buen seguro hallarán desarrollo más extenso y completo en la monografía que prepara el editor sobre el poema.

La edición en tres volúmenes que tenemos ahora entre las manos constituye, en esencia, la transcripción del único manuscrito, autógrafo y supervisado por el autor, que conserva el poema y que en la actualidad se custodia en la lisboeta $\mathrm{Bi}$ blioteca da Ajuda (ejemplar 50-I-38). Hablo de transcripción pero bien podría calificarla de reconstrucción dado el precario estado de conservación del mismo (hay partes perdidas irremediablemente, numerosas manchas de húmedad, el papel ha oscurecido en muchos pasajes y otros agentes han complicado de forma ostensible su legibilidad). A todo ello se suma la presencia de errores de copia del autor, quizás a causa del cansancio y a su ya avanzada edad en las fases finales de elaboración del manuscrito, errores en la numeración autógrafa y la presencia de folios intercalados en una revisión posterior, entre otros elementos, así como la extensión del texto, que ha convertido esta transcripción en una labor que ha necesitado años de dedicación por parte del profesor Escobar. Los criterios seguidos por el editor son claros y expuestos por él mismo en el apartado final de su estudio preliminar: «La razón principal para conservar el sistema ortográfico original y otros elementos que conforman el usus scribendi de Mal Lara obedece a un único deseo, esto es, acercarnos, en la medida de lo posible, a su voluntad autorial» (282). Por ello, el texto no se ha modernizado más que en la puntuación y en casos muy puntuales. Tampoco está anotado, fiando presumiblemente la lectura que esta intervención implica a la monografía anunciada. Sí se ofrece, no obstante, un aparato crítico final con los errores de copia detectados, variantes y reescrituras. Dadas las notables dificultades de lectura del testimonio, apenas esbozadas en este párrafo, entenderá el lector la envergadura de este proyecto editorial y la ausencia de un aparato de notas.

No acaba aquí, empero, la labor emprendida por el profesor Escobar, puesto que acompaña la transcripción del poema en tres extensos volúmenes de un estudio preliminar que ronda las 300 páginas donde, además de apuntar las cuestiones relativas a la lectura global del poema tratadas arriba, aborda sobre todo el análisis de las fuentes, los motivos y las técnicas compositivas del autor. Y cabe decir que no es tarea fácil, si se tiene en cuenta que Mal Lara reconoce haber manejado más de doscientas autoridades. Así pues, el grueso del estudio preliminar puede dividirse en tres grandes secciones, dedicadas a la caracterización genérica del poema (62-118), las fuentes y temas (118-168) y los recursos técnicos (168255). En la primera se aborda la presencia de elementos procedentes de otros géneros con los que la épica del Hércules guarda relación. Tal es el caso de la dimensión alegórica y los exempla mitológicos, pasando por los cuentos, la novela bizantina, sentimental y morisca, los libros de caballerías y de hadas, la poesía de cancionero e, incluso, la tragedia y la comedia. Como puede verse, estamos ante un poema de factura compleja y erudita, obra de un hombre de letras, perteneciente a un entorno académico antes que cortesano, y que, por lo tanto, 
perfila una idea de épica muy distinta de la escrita por hombres de armas, la más característica del panorama épico hispano, en especial si se la compara con La Araucana. Una épica, sin duda, alentada por idéntico sentimiento patriótico pero que auspicia una escritura que se mueve por sendas muy distintas, cultas y cultistas, y que halla acomodo en la elección de una lengua voluntariamente oscura como la defendida por Mal Lara en la Declaración. Semejante voluntad se manifiesta de modo igual de evidente en la elección de las autoridades imitadas y los temas analizados en el siguiente apartado, que el editor repasa aduciendo ejemplos que compara con los de sus fuentes. Esta comparación ofrece un análisis que sin ánimo de querer ser exhaustivo (bien podría decirse que es imposible) sí que busca centrarse en el detalle y en el estudio del pasaje paralelo y sus múltiples desviaciones, fruto del manejo de más una fuente. Se ve a las claras que el editor conoce muy bien la obra y aporta ejemplos de la más variada traza para demostrar el caso particular que analiza. Cierra el estudio, por último, un repaso de los recursos compositivos empleados por el autor, de los que Escobar elabora un panorama general.

En definitiva, el estudio preliminar que acompaña la edición del Hércules animoso posee una naturaleza descriptiva, que busca dar cuenta de la complejidad del poema y que sostiene su análisis en la revisión de casos concretos en el marco de una lectura del poema esbozada en dos apartados. Esta lectura se construye, también, por medio de la comparación y el cotejo constantes con la obra del humanista, en particular de La Psyche, que el editor conoce muy bien. No en vano el profesor Escobar es un experto reconocido en la figura del humanista. Siendo una aportación encomiable para la configuración de la cultura sevillana y española del Quinientos debería de incardinar también el poema en la épica habsbúrgica ya que, a mi juicio, esta edición del Hércules supone la recuperación de una obra de Mal Lara antes que la de un poema épico, lo cual no es un demérito sino simplemente una cuestión de enfoque y perspectiva, y por ello esperamos con gran interés la prometida monografía. 


\section{Bibliografía}

Alves, Hélio J.S., Camóes, Corte-Real e o sistema da epopeia quinhestinta, Coimbra, Universidade, 2001.

Blanco, Mercedes, Góngora heroico: las «Soledades» y la tradición épica, Madrid, Centro de Estudios Europa Hispánica, 2012.

Caravaggi, Giovanni, Studi sull'epica ispanica del Rinascimento, Pisa, Università, 1974.

Chevalier, Maxime, L'Arioste en Espagne (1530-1650). Recherches sur l'influence $d u$ «Roland furieux», Bordeaux, Institut d'études ibériques et ibéro-américains de l'Université de Bordeaux, 1966.

Сirot, George, «Coup d'œil sur la poésie épique du Siècle d'Or», Bulletin Hispanique, 48 (1946), 294-329.

Davis, Elizabeth B., Myth and Identity in the Epic of Imperial Spain, Columbia and London, University of Missouri Press, 2001.

La poesía épica en el Siglo de Oro, Criticón, 115 (2012). Número monográfico coordinado por Rodrigo Cacho Casal.

Lara Garrido, José, Los mejores plectros. teoria y práctica de la épica culta en el Siglo de Oro, Málaga, Analecta Malacitana, Anejo XXIII, Universidad de Málaga, 1999.

Pierce, Frank, La poesía épica del Siglo de Oro, Madrid, Gredos, 1968.

Prieto, Antonio, "Origen y transformación de la épica culta en castellano», Analecta Malacitana, 2 (1979), 193-243.

Vega, María José y VILÀ, Lara (eds.), La teoría de la épica en el siglo XVI (España, Francia, Italia y Portugal), Vigo, Editorial Academia del Hispanismo, 2010.

VILÀ, Lara, Épica e imperio. Imitación virgiliana y propaganda política en la épica española del siglo XVI, Tesis doctoral, Universitat Autònoma de Barcelona, 2001. 